\title{
How Should Medicine Develop? A Comparative Analysis of Cost-Benefit and Cost-Effectiveness of All Types of Evidence-Based Medicine for All Clinical Conditions (Report from Work-In-Progress)
}

\section{Søren Ventegodt ${ }^{13 *}$}

${ }^{1}$ Quality of Life Research Center, Copenhagen, Denmark

${ }^{2}$ Research Clinic for Holistic Medicine, Denmark

${ }^{3}$ Nordic School of Holistic Medicine, Copenhagen, Denmark

One question is often asked when it comes to medicine: How should it develop? Where should it go? In this editorial I will report on the work-in-progress from our group, as I feel it this analysis might be useful for national health care planners, universities making 10-year plans for teaching etc. in spite of not being perfect. A more final analysis will hopefully soon be published.

Please allow me first to suggest that the five major categories of CAM used by NCCAM are reorganized into a 10-class system for evidencebased medicine in general [1], as the viewpoint often presented in JAMA that CAM seems fair: CAM and drug-based medicine (biomedicine) must be one and integrated into a total medical system including all evidence-based medicine [2] (Table 1).

Such a system allows us to examine, with some uncertainty, the cost-benefit and cost-efficiency of these 10 different types of evidencebased medicine, so we can get an idea of where to go with medicine in the future. It seems relevant to look at the ration: Benefit to Harm (often called Therapeutic Value, or TV), the cost of the production of quality of life (QALY) and self-rated health (HALY).

Now, let us look at cost-benefit for these different types of medicine. Today there are three major population health measures permitting morbidity and mortality to be simultaneously evaluated: QALYs (quality of life-adjusted life years), HALYs (health-adjusted life years) and DALYs (disability- adjusted life years). In this paper I will only estimate QALYs and HALYs.

We need to estimate the general numbers and this is best done

1. Chemical medicine (biomedicine with bioactive molecules)

2. Chemical CAM (flower medicine, herbal medicine, diets, minerals, vitamins etc.)

3. Body-medicine (Low-energy types: massage, reflexology, physical therapy, physiotherapy, spa, sauna etc; High-energy times: chiropractics etc.)

4. Mind-medicine (psychotherapy-psychodynamic, cognitive, gestalt etc.psychoanalysis, meditation, no-touch sexology, couching, healing music)

5. Spirit-medicine (philosophical interventions, energy medicine, prayers, spiritual healing (i.e. Reichi), shamanism, spiritual CAM (i.e. crystal healing) etc.)

6. Mind-body medicine (acupuncture, acupressure, homeopathy, manual sexology, body-psychotherapy, Reichian bodywork, Rosen therapy, ergo therapy etc.)

7. Body-spirit medicine (prayer involving physical activity like in Tibetan Buddhiststyle meditation, pilgrimage etc.)

8. Holistic body-mind-spirit medicine-including existential therapy (holistic medicine, clinical medicine, clinical holistic medicine, holistic body-psychotherapy, holistic bodywork, the sexological examination, holistic mind-body medicine, biodynamic body-psychotherapy, tantric bodywork and massage, holistic sexology, Native American rituals).

9. Chemical-body-mind-spirit medicine (shamanism with peyote, Ayuhuasca, magic mushrooms, Grof's LSD-psychotherapy etc.)

10. Social and environmental medicine (coaching, work-related personal development programs, stress management, leadership training, gardening, aesthetic architecture, Feng Shui etc

Table 1: Classification of medicine (including CAM and biomedicine) into 10 principal classes, Class 1 and 2 are chemical medicines; 3-10 are informational medicines. using meta analyses, preferably Cochrane reviews. It would be good to include estimates from the leading medical journals of typical numbers of NNTs and NNHs. But to make such a highest-level analysis where we look at all types of medicine for all clinical conditions we will need to simplify matters.

The prize of pharmaceutical drugs can easily be calculated, i.e. from the Danish cost of drugs prescribed to more than two million chronic patients in Denmark using biomedicine. If the prize of CAM treatments also are set from Danish circumstances a year of therapy often is about 20 session at a cost of around $2000 €$. (In developing countries the prize of drugs are often $50 \%$ of the Danish prizes but CAM is often a tenth). The calculation of QALY and HALY can be based on the knowledge on normal loss of quality of life and self-rated health when people get ill in Denmark. Results can be calculated based on estimate numbers with an uncertainty of $\pm 100 \%$,

As the biggest problem in medical research today is bias from economical interests, we should avoid sources that might be strongly biased, like RCTs from pharmaceutical industry, overoptimistic estimates in reviews from CAM-journals not represented in MedLine/ www.PubMed.gov etc.

Actually the process of limiting bias has been our biggest problem in this work, forcing us to leaving out most of the sources often used in this type of analyses, like statistics made by public organs headed by people close to the pharmaceutical industry. Such statistics seems mostly to be extremely biased in favor of biomedicine.

There are many fundamental problems in biomedicine I could have addressed to make this study more thorough; there are problems from the practical use of drugs with low compliance, wrong diagnosis, errors in prescriptions and overmedication; there are problems with the RCTs at its very roots making the NNT and $\mathrm{NNH}$ numbers from industrial testing difficult to trust, and even the best of estimates are after all based on numbers coming from the pharmaceutical industries use of the RCT in testing its products. So I know that we are only scratching the surface of the problems in this analysis.

*Corresponding author: Søren Ventegodt, MD, MMedSci, EU-MSc-CAM Director, Quality of Life Research Center, Frederiksberg Allé 13A,2.t.v., DK-1820 Copenhagen V, Denmark, Tel: +45-33-141113; E-mail: ventegodt@livskvalitet.org

Received October 31, 2013; Accepted November 01, 2013; Published November 04, 2013

Citation: Ventegodt S (2013) How Should Medicine Develop? A Comparative Analysis of Cost-Benefit and Cost-Effectiveness of All Types of Evidence-Based Medicine for All Clinical Conditions (Report from Work-In-Progress). Altern Integ Med 2: e108. doi:10.4172/2327-5162 1000e108

Copyright: (c) 2013 Ventegodt S. This is an open-access article distributed unde the terms of the Creative Commons Attribution License, which permits unrestricted use, distribution, and reproduction in any medium, provided the original author and source are credited. 
Based on the Cochrane library we have evaluated the benefit and harm from pharmaceutical drugs and the different CAM systems. We have looked at the likelihood to benefit using Number Needed to Treat (NNT), the likelihood to be harmed by the different adverse effects/ side effects by using Number Needed to treat to Harm (NNH), and the total likelihood to get one side effect/adverse reaction or adverse event (NNH total) and from this we have calculated the ratio "benefit to harm" called the Therapeutic Value of the treatment (TV=NNH ${ }_{\text {total }}$ l NNT) [3-5], for the 10 different types of medicine (Table 2).

While it for a long time, thanks to the many Cochrane reviews, has been easy to find NNT and NNH numbers for most pharmaceutical drugs, it has been more difficult to establish NNT and NNH numbers for the many different types of holistic and alternative medicine (CAM), and the relative harm of non-drug medicine had to be estimated from the number of reported cases in the literature [6]. Recently more than hundred Cochrane reviews have been made on a large number of CAM-types for a large number of clinical conditions, and NCCAM, the US research center for CAM, has published a number of reports on five major categories of CAM, allowing us for a far better estimate of NNHs and NNTs $[7,8]$ (Table 2). As an example NCCAM has evaluated the number of patients treated every year in the US with massage therapy (therapeutic touch) and the number of patients experiencing significant side effects from such treatments; NCCAM found that 20,000,000 adults and 700.000 children are treated every year with very few patients harmed [9], allowing us to estimate $\mathrm{NNH}>1,000,000$ for massage and similar types of therapeutic touch. Of the 145 Cochrane reviews of CAM analyzed by "Committee on the Use of Complementary and Alternative Medicine by the American Public" (8) 38.4\% of the reviews showed a positive or possibly positive (12.4\%) effect. These Cochrane reviews documented typical NNTs of 2-30, depending on CAM type, and typical NNHs of 1000-1.000.000. Typical NNTs and NNHs for the 10 types of evidence-based medicine are presented in (Table 2) [3,5].

Two things are especially interesting for patient: 1) How efficient is the medicine? This is best known from Number Needed to Treat (NNT) telling how likely it is that the patient will benefit from the treatment. 2) How harmful is the medicine. The absolute harm is important but even more important is the ratio benefit to harm. Many patients will feel that a treatment is of therapeutic value if its advantages (statistically) dominate its disadvantages. The ratio benefit to harm is simplest expressed by the ratio $\mathrm{TV}=\mathrm{NNH}_{\text {total }} / \mathrm{NNT}$, where NNTtotal is the total likelihood of getting a side/adverse effect or adverse event. Typical values of $\mathrm{HHN}_{\text {total }}$ and TV can also be found in Table 2 .

In general chemical medicine, whether biomedical drugs or CAM (herbs, aromatic oils, diet changes etc) have high $\mathrm{NNH}_{\text {totals }}$ and low TVs. The effect of chemical CAM seems to be less than pharmaceutical drugs, but it is a lot safer (Table 2) [3-11]

If you manipulate the biological informational system of the patient (for the scientific concept of biological information, [12]) instead of body chemistry, you seem to avoid side/adverse effects and adverse events. Some types of CAM have a low efficacy, but still the TV is high because of the relative safeness. Some types of CAM are both efficient and safe. Holistic mind-body medicine seems to be as safe as other kinds of CAM but more efficient and there has the highest TV. Interestingly, there are adverse effects of the drugs traditionally used in shamanism [6], giving shamanistic medicine the lowest TV of all CAM treatments; but if you look at the cost during a 50 years life span, Shamanism ends up looking the best of all known treatments (Table 3). As I do not want to return to Shamanism, I would like to give our tribute to the pre-modern medicine. Indigenous people often know much about medicine.

The cost of different drugs and different CAM treatment varies a great deal. Within every class of evidence-based medicine there are expensive and cheap alternatives. I have found I fair to set both a pharmaceutical and a CAM treatment to $2000 €$ per year, knowing that praying is cheaper and cancer-chemotherapy is more expensive. If you know the NNT-number and the cost of one patient treated, you can find the cost for one patient cured (or at least treated successfully) by multiplying these numbers (Cost of one patient cured=NNT $x$ yearly treatment cost) (Table 3). The next year the cured patients will not cost anything but the patient not cured will still cost the yearly treatment cost. In this way can I estimate the 10 and 50 years cost of one patient

\begin{tabular}{|c|c|c|c|c|c|}
\hline \multirow[t]{3}{*}{ CAM class } & Short term effect & Long term effect & \multirow[t]{2}{*}{ Side effects/adverse events } & \multirow[t]{2}{*}{ Total risk of harm } & Therapeutic Value \\
\hline & (0-6 month) & (6-24 month) & & & $\mathrm{TV}=\mathrm{NNH}_{\text {total }} / \mathrm{NNT}$ \\
\hline & NNT & NNT & NNH & $\mathrm{NNH}_{\text {total }}$ & TV (6-24 month) \\
\hline Class 1-Biomedicine (pharmaceuticals) & $20(5-50)$ & $50(5-100)$ & $1-5$ & $1-3$ & $1-0.01$ \\
\hline Class 2-CAM (Chemical CAM) & $\geq 20$ & $\geq 50$ & 25 (allergy) & 25 & 0.5 \\
\hline $\begin{array}{l}\text { Class 3a-CAM (Physical therapy, low-energy i.e. } \\
\text { massage, therapeutic touch) }\end{array}$ & $2-4$ & 6 & $>1.000 .000$ & $>1.000 .000$ & 167.000 \\
\hline $\begin{array}{l}\text { Class 3b-CAM (Physical therapy, high-energy i.e. } \\
\text { chiropractic treatment) }\end{array}$ & $2-4$ & 6 & 1000 & & \\
\hline (fractures) & 1000 & 167 & & & \\
\hline Class 4-CAM (Psychotherapy)* & 3 & 6 & $>1.000 .000$ & $>1.000 .000$ & 167.000 \\
\hline Class 5-CAM (Spiritual therapy) & $>10$ & $>20$ & $>1.000 .000$ & $>1.000 .000$ & 50.000 \\
\hline Class 6-CAM (Mind-Body medicine) & 2 & 4 & $>1.000 .000$ & $>1.000 .000$ & 250.000 \\
\hline Class 7-CAM (Body-Spirit medicine) & Not known & Not known & $>1.000 .000$ & $>1.000 .000$ & Not known \\
\hline Class 8-CAM (Holistic mind-body medicine) & 2 & $1-2^{* *}$ & $>1.000 .000$ & $>1.000 .000$ & $500.000-1.000 .000$ \\
\hline Class 9-CAM (Shamanism w. drugs etc.) ${ }^{* * *}$ & 1 & 1 & $>1000$ & $>1000$ & $>1000$ \\
\hline Class 10-CAM (Social medicine) & 1 & 10 & $>1.000 .000$ & $>1.000 .000$ & 100.000 \\
\hline
\end{tabular}

*Some types of psychotherapy have short-term NNTs of 2-3 (STPP) and long term NNTs of 1-2 (LTPP) for mental, somatic and sexual health problems [3,10].

**The effect of clinical holistic medicine and similar medical systems seem to continue to increase though time [11]. NNT: Number Needed to Treat. NNH: Number Needed to Harm, $\mathrm{NNH}_{\text {total }}$ : Total likelihood of getting one side effect/adverse effect or adverse event. TV: Therapeutic Value, which here means ratio of benefit to harm. For a treatment to be of true value to patients, is must be efficient, with a low NNT number, and a high TV-number.

${ }^{* * *}$ Adverse effects, mostly brief reactive psychoses, are only seen with mentally ill patients [6].

Table 2: Typical numbers for effect and harm, and the ration of benefit to harm for 10 classes of evidence-based medicine (NNTs, NNHs, NNH totals and TVs) (estimated from Cochrane reviews of RCTs and from clinical studies with chronic patients [3-10]. 
Citation: Ventegodt S (2013) How Should Medicine Develop? A Comparative Analysis of Cost-Benefit and Cost-Effectiveness of All Types of EvidenceBased Medicine for All Clinical Conditions (Report from Work-In-Progress). Altern Integ Med 2: e108. doi:10.4172/2327-5162.1000e108

Page 3 of 5

\begin{tabular}{|c|c|c|c|c|}
\hline \multirow{3}{*}{$\begin{array}{l}\text { Continuous treatment (only stopped } \\
\text { if the patients gets cured) }\end{array}$} & \multirow{2}{*}{\begin{tabular}{|c|}
$\begin{array}{c}\text { Number of patients harmed } \\
\text { For one patient cured }\end{array}$ \\
Self-rated health \\
\end{tabular}} & \multicolumn{3}{|c|}{ Accumulated harm (number of patients harmed per patient cured) } \\
\hline & & per cured patient & per cured patient & per cured patient \\
\hline & $\mathrm{NNH}_{\text {total }}$ & First year & Year 10 & Year 50 \\
\hline \multicolumn{5}{|l|}{ Medicine with drugs } \\
\hline Class 1-Chemical medicine & 3 & 17 & 25 & 50 \\
\hline Class 2-CAM (Chemical CAM) & 25 & 2 & 4 & 5 \\
\hline \multicolumn{5}{|l|}{ Non-drug CAM } \\
\hline Class 3a-CAM (Physical therapy, Low E) & $1,000,000$ & $0.000,01$ & $0.000,1$ & 0.001 \\
\hline Class 3b-CAM (Physical therapy, High E.) & 1,000 & 0,002 & 0,01 & 0,1 \\
\hline Class 4-CAM (Psychotherapy) & $1,000,000$ & $0.000,01$ & $0.000,1$ & 0.001 \\
\hline Class 5-CAM (Spiritual therapy) & $1,000,000$ & Not known & Not known & Not known \\
\hline Class 6-CAM (Mind-Body medicine) & $1,000,000$ & $0.000,01$ & $0.000,1$ & 0.001 \\
\hline Class 7-CAM Body-Spirit medicine & $1,000,000$ & Not known & Not known & Not known \\
\hline Class 8-CAM (Holistic mind-body medicine) & $1,000,000$ & $0.000,01$ & $0.000,1$ & 0.001 \\
\hline Class 9-CAM (Shamanism w. drugs) & 1,000 & 0.001 & 0.001 & 0.001 \\
\hline Class10-CAM (Social/environm. medicine) & $1,000,000$ & $0.000,01$ & $0.000,1$ & 0.001 \\
\hline
\end{tabular}

Table 3: Accumulated harm through time (year one, ten and fifty) for 10 classes of evidence-based medicine-prize for one patient cured.

\begin{tabular}{|c|c|c|c|c|}
\hline \multirow{3}{*}{$\begin{array}{l}\text { Continuous treatment (only stopped } \\
\text { if the patients gets cured) }\end{array}$} & \multirow{2}{*}{$\begin{array}{c}\text { Cost per } \\
\text { patient-year }\end{array}$} & \multicolumn{3}{|c|}{ Accumulated cost $(€)$} \\
\hline & & per cured patient & per cured patient & per cured patient \\
\hline & First year & First year & Year 10 & Year 50 \\
\hline \multicolumn{5}{|l|}{ Medicine with drugs (chemical medicine) } \\
\hline 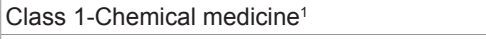 & 2,000 & $\geq 100,000$ & $\geq 200,000$ & $\geq 1,000,000$ \\
\hline Class 2-CAM (Chemical CAM) & 2,000 & $>100,000$ & $>200,000$ & $>1,000,000$ \\
\hline \multicolumn{5}{|l|}{ Non-drug CAM (informational medicine) } \\
\hline Class 3-CAM (Physical therapy) & 2,000 & 12,000 & 60,000 & 100,000 \\
\hline Class 4-CAM (Psychotherapy) & 2,000 & 12,000 & 60,000 & 100,000 \\
\hline Class 5-CAM (Spiritual therapy) & Not known & Not known & Not known & Not known \\
\hline Class 6-CAM (Mind-Body medicine) & 2,000 & 8,000 & 30,000 & 50,000 \\
\hline \multicolumn{5}{|l|}{ Class 7-Body-Spirit medicine } \\
\hline Class 8-CAM (Holistic mind-body medicine) & 2,000 & 5,000 & 10,000 & 20,000 \\
\hline Class 9-CAM (Shamanism w. drugs) & 500 & 600 & 800 & 2,000 \\
\hline Class 10-CAM (Social/environm. medicine) & 5.000 & 50.000 & 350.000 & 500.000 \\
\hline
\end{tabular}

${ }^{1}$ Cost of biomedical examination, hospitalization, and treatment of adverse effects and events not included (estimated round numbers, see text)

Table 4: Accumulated cost (number of patient with side effects/adverse effects and adverse events) for one patient cured through time (year one, ten and fifty) for 10 classes of evidence-based medicine.

Continuous treatment (only stopped if the patients gets cured)
QOL improvement from treatment (\%)

if successful

Global QOL
Prize of one QALY calculated from NNT and accumulated cost (Table 3 )

\begin{tabular}{|c|c|}
\hline per cured patient & per cured patient \\
\hline Year $\mathbf{1 0}$ & Year $\mathbf{5 0}$ \\
\hline
\end{tabular}

Medicine with drugs (chemical medicine)

Class 1-Chemical medicine ${ }^{1}$

Class 2-CAM (Chemical CAM)

Non-drug CAM (informational medicine)

Class 3-CAM (Physical therapy)

Class 4-CAM (Psychotherapy)

Class 5-CAM (Spiritual therapy)

Class 6-CAM (Mind-Body medicine)

Class 7-CAM Body-Spirit medicine

Class 8-CAM (Holistic mind-body medicine)

Class 9-CAM (Shamanism w. drugs)

Class 10-CAM (Social/environm. medicine)

\begin{tabular}{|l|c|c|c|}
\hline $20 \%$ & 500,000 & $\geq 1,000,000$ & $\geq 5,000,000$ \\
\hline $20 \%$ & $>500,000$ & $>1,000,000$ & $>5,000,000$ \\
\hline \multicolumn{3}{|c|}{} & \\
\hline $20 \%$ & 60,000 & 300,000 & 60,000 \\
\hline $20 \%$ & 60,000 & 300,000 & 60,000 \\
\hline $20 \%$ & Not known & Not known & Not known \\
\hline $20 \%$ & 40,000 & 180,000 & 40,000 \\
\hline $20 \%$ & Not known & Not known & 10,000 \\
\hline $20 \%$ & 25,000 & 50,000 & 800 \\
\hline $20 \%$ & 3000 & 4000 & $2,500.000$ \\
\hline
\end{tabular}

${ }^{1}$ Cost of biomedical examination, hospitalization, and treatment of adverse effects and events not included) (estimated round numbers, see text)

Table 5: Accumulated cost of one QALY (Quality of life-adjusted Life Year) through time (year one, ten and fifty) for 10 classes of evidence-based medicine.

cured (Table 4). If the NNT is very high, very few patients get cured and most become chronic patient. This is the case for pharmaceutical drugs so here the calculation is simple: The cost as times goes by is calculated as yearly cost $\mathrm{X}$ time. If all or most patients are cure in one or a few years, the calculation is similar simple: The total treatment cost is the one year treatment cost. When patients get better little by little, as in 


\begin{tabular}{|c|c|c|c|c|}
\hline \multirow[t]{3}{*}{$\begin{array}{l}\text { Continuous treatment (only stopped } \\
\text { if the patients gets cured) }\end{array}$} & \multirow{2}{*}{$\begin{array}{c}\text { Health improvement } \\
\text { from treatment (\%) } \\
\text { if successful }\end{array}$} & \multicolumn{3}{|c|}{$\begin{array}{c}\text { Prize of one HALY calculated from NNT } \\
\text { and accumulated cost (Table } 3 \text { ) }\end{array}$} \\
\hline & & per cured patient & per cured patient & per cured patient \\
\hline & & First year & Year 10 & Year 50 \\
\hline \multicolumn{5}{|l|}{ Medicine with drugs } \\
\hline Class 1 -Chemical medicine ${ }^{1}$ & $20 \%$ & 500,000 & $\geq 1,000,000$ & $\geq 5,000,000$ \\
\hline Class 2-CAM (Chemical CAM) & $20 \%$ & $>500,000$ & $>1,000,000$ & $>5,000,000$ \\
\hline \multicolumn{5}{|l|}{ Non-drug CAM } \\
\hline Class 3-CAM (Physical therapy) & $20 \%$ & 60,000 & 300,000 & 60,000 \\
\hline Class 4-CAM (Psychotherapy) & $20 \%$ & 60,000 & 300,000 & 60,000 \\
\hline Class 5-CAM (Spiritual therapy) & $20 \%$ & Not known & Not known & Not known \\
\hline Class 6-CAM (Mind-Body medicine) & $20 \%$ & 40,000 & 180,000 & 40,000 \\
\hline Class 7-CAM Body-Spirit medicine & $20 \%$ & Not known & Not known & Not known \\
\hline Class 8-CAM (Holistic mind-body medicine) & $20 \%$ & 25,000 & 50,000 & 10,000 \\
\hline Class 9-CAM (Shamanism w. drugs) & $20 \%$ & 3000 & 4000 & 800 \\
\hline Class 10-CAM (Social/environm. medicine) & $20 \%$ & 250.000 & $1,750.000$ & $2,500.000$ \\
\hline
\end{tabular}

${ }^{1}$ Cost of biomedical examination, hospitalization, and treatment of adverse effects and events not included) (estimated round numbers, see text)

Table 6: Accumulated cost of one HALY (Quality of life-adjusted Life Year) through time (year one, ten and fifty) for 10 classes of evidence-based medicine.

psychotherapy, a more complicated estimate must be made, accounting for the current recovery of patients. Our estimates of all ten classes are found in Table 4. Due to lack of data I could not make estimates for Class 5 and 7.

If there are many adverse effects and events these cost sick-days, hospitalization etc. I know that drugs are always poisonous to some extent, and that it is estimated that there are now 100,000 deaths a year in US hospitals directly caused by pharmaceutical drugs [13]. This is a huge cost but I have only included the direct cost to the drugs in our estimate. The true cost is likely to be several times larger.

A popular effect measure is QALY, or Quality Adjusted Life Years. The idea is simple: Survival has in itself no value; if you survive but suffer to en extreme extent it might be better if the doctor had not saved you in the first place. The secure that the patient gets value for money, the cost per QALY must be calculated. As QOL of life in general is $20 \%$ lower for ill people than for healthy [14] I can make a simple estimate of cost/QALY, presented in Table 4. The principles of the estimate are simple: If a patient is cured right away and stays healthy, and would have become a chronic patient without treatment, the cost for one cured patient is multiplied with the time the patient's health is improved. As very few patients are cured with biomedicine, the cost of one QALY becomes astronomic as the treatment continues for life without results-which is normally the case in Denmark where I have socialized biomedicine, free or very cheap for all chronic patients. On the other hand will a QALY-unit, with an efficient CAM cure, with normally has the extra plus that patients not only stays healthy but also improves health through time (as they have learned the basic principles for human development) as times go by be relatively cheaper. For every past year the quality of life and health is already paid, as shown in Table 5. Interestingly one-session shamanistic healing is far the cheapest kind of medicine, presumably explaining its great popularity in almost all pre-modern cultures. In one-session healing you are normally taken unto a daylong journey of guided self-exploration where you come to understand how you make yourself ill by the way you life and look at things. It's thus a life-style and philosophy of life intervention. From a theoretical point of view it might actually work.

Instead of QALYs, WHO often recommend the use of HALYs (and DALYs), which is exactly the same, only with health (most often selfrated health) instead of quality of life. I know that the strongest measure of health is self-rated health [15-18], and I also know that sick people experience there health very much the same way as they experience their quality of life [14] allowing us again to use a difference of $20 \%$ between healthy and ill people. This gives us Table 6, showing that mind-body medicine gives lots of health for the money, while chemical medicine and social medicine does not.

The harm caused by the 10 different types of evidence-based medicine as times goes by has been estimated in Table 6. Patients using biomedicine for years without being cured, as is normally the case, are accumulating the harmful adverse effects and events caused by the pharmaceutical drugs. Non-drug CAM does not cause significant harm. The hallucinogenic drugs have some rare, but significant adverse effects but as shamanistic medicine is often very efficient with result that last for life due to increase self-awareness and self-insight, the harm inflicted over a life-span becomes similar to the level of harm inflicted by the other CAM systems, indicating that I might be more open to the potential benefits of pre-modern medicine and drug-induced one session healing, like Grof's LSD therapy [19].

For a society the most important thing is to choose a medicine that is affordable, which in general benefits the patients, without harming them. Table 3 shows the sad consequences of the large $\mathrm{NNH}$ and $\mathrm{NNH}_{\text {total }}$ numbers of the chemical medicine in the long run. As one of three patients are harmed every year with pharmaceutical drugs, and treatment often continues for life when the patient is not cured, the consequence is that almost every patient is harmed in the end, and 50 patients are harmed for every single, chronic patient helped or cured. In Denmark over 2 million chronic patients out of a population of 5 millions uses drugs for about 6 billion Euros pr. Year (or 2-3,000 EURO per chronically ill patient, confirming the prize of drugs used in Table 4). It is clear for us that the same money spent on the most efficient types of non-drug CAM (group 3,4,6,8) would do immensely more for the populations health.

As this is not new, one wonders why chemical medicine is so much used, and why mind-body medicine is not part of the official health system. One likely explanation is the close connection between pharmaceutical industry, the physicians and the public health systemoften called the "medico-industrial complex". This system is often seen to actively work against CAM, repressing CAM researchers and effectively by all means keeping CAM out of the political scene [20]. 
Citation: Ventegodt S (2013) How Should Medicine Develop? A Comparative Analysis of Cost-Benefit and Cost-Effectiveness of All Types of EvidenceBased Medicine for All Clinical Conditions (Report from Work-In-Progress). Altern Integ Med 2: e108. doi:10.4172/2327-5162.1000e108

Page 5 of 5

Drugs obviously turn patients into chronic patients instead of curing them. Half the population of the western world today is chronically ill, seemingly because of strong political and financial interests in biomedicine, leading to massive oppression of CAM in favor of drugs.

The shift from drugs to CAM would improve health radically in the society and reduce the cost of healthcare to a small fraction. Strict laws should be introduced immediately in all countries to stop the pharmaceutical industry and its collaborates from promoting drugs without evidence of therapeutic value (the ratio benefits: harm larger being no less than 1) and long term effect and patient safety, and from repressing CAM.

Strong economical and political interest seem to control medicine in Denmark and many other countries, making the pharmaceutical drugs often used, in spite of better and safer alternative for almost all clinical conditions (for comprehensive lists of clinical conditions that can be helped or cured with mind-body medicine $[3,10])$.

People who still doubt the reality of the low cost, high efficacy and safety of CAM presented in this review are encouraged to study Dean Ornish cure for coronary heart disease. It was this well-documented CAM cure for a serious disease that made us believe in the potentials of CAM [21,22].

We have seen that the 10 different types of evidence-based medicine have very different profiles when it comes to efficacy, cost pr. cured patient, cost per QALY, cost per HALY, and cost in harm on patients. In general chemical medicine, biomedicine as well as CAM, is expensive and harmful in the long run, while CAM i.e. massage therapy and psychotherapy is safe.

The best types of CAM, like mind-body medicine, holistic mindbody medicine (i.e. the classical Hippocratic medicine, often called clinical holistic medicine/CHM) are 50.000 times less harmful and 100 times more efficient in producing health and happiness (quality of life). The cost of one cured chronic patient is about $1,000,000 €$ with pharmaceutical drugs and $100,000 €$ or less with the efficient types of CAM.

Surprisingly we find pre-modern medicine-shamanism-to win the race in the end. While the drugs used often have some rare adverse effects, the efficacy of traditional one-session healing might make shamanistic medicine the cheapest, safest and most effective in the end. While I do not advocate the back-propagation to pre-modern times, I find it very interesting that such a medicine exists, inspiring us all to continue our quest for a still better medicine.

\section{References}

1. Ventegodt $S$, Merrick S. Developing NCCAMs five category system for CAM into a new 10 class categorical system for all types of medicine, based on four levels of human existence: molecules, body, mind and spirit. In preparation.

2. Fontanarosa PB, Lundberg GD (1998) Alternative medicine meets science. JAMA 280: 1618-1619.

3. Ventegodt S, Andersen NJ, Kandel I, Merrick J (2009) Comparative analysis of cost-effectiveness of non-drug medicine (non-pharmaceutical holistic, complementary and alternative medicine/CAM) and biomedicine (pharmaceutical drugs) for all clinical conditions. Int J Disabil Hum Dev 8: 245 256.

4. Ventegodt S, Merrick J (2010) Therapeutic value (TV) of treatments with pharmaceutical drugs. Rough estimates for all clinical conditions based on Cochrane reviews and the ratio: Number Needed to Harm/Number Needed to Treat $(\mathrm{TV}=\mathrm{NNH}$ total $/ \mathrm{NNT})$.

5. Ventegodt S, Merrick J (2010) Therapeutic value (TV) of alternative medicine (non-drug CAM). Rough estimates for all clinical conditions based on Cochrane reviews and the ratio: Number Needed to Harm/Number Needed to Treat (TV=NNHtotal/NNT). BMJ.

6. Ventegodt S, Merrick J (2009) A Review of side effects and adverse events of non-drug medicine (nonpharmaceutical complementary and alternative medicine): Psychotherapy, mind-body medicine and clinical holistic medicine. J Complement Integr Med 6: 16.

7. http://nccam.nih.gov/ (accessed 2010-11-22)

8. Committee on the Use of Complementary and Alternative Medicine by the American Public (2005) Complementary and Alternative Medicine (CAM) in the United States. Washington, DC: National Academies Press.

9. National Center for Complementary and Alternative Medicine. Massage Therapy: An Introduction. 2006. Bethesda, Maryland. NCCAM.

10. Ventegodt S, Omar H, Merrick J (2009) Quality of Life as Medicine: Interventions that Induce Salutogenesis. A Review of the Literature. Social Indicator Research.

11. Ventegodt S, Thegler S, Andreasen T, Struve F, Enevoldsen L, et al. (2006) Clinical holistic medicine: psychodynamic short-time therapy complemented with bodywork. A clinical follow-up study of 109 patients. ScientificWorldJournal 6: 2220-2238.

12. Ventegodt S, Hermansen TD, Flensborg-Madsen T, Nielsen ML, Clausen B, et al. (2006) Human development V: biochemistry unable to explain the emergence of biological form (morphogenesis) and therefore a new principle as source of biological information is needed. ScientificWorldJournal 6: 13591367.

13. Lazarou J, Pomeranz BH, Corey PN (1998) Incidence of adverse drug reactions in hospitalized patients: a meta-analysis of prospective studies. JAMA 279: 1200-1205.

14. Ventegodt S (1995) Quality of life in Denmark. Results from a population survey. Copenhagen: Forskningscentrets Forlag.

15. Long MJ, McQueen DA, Bangalore VG, Schurman JR 2nd (2005) Using selfassessed health to predict patient outcomes after total knee replacement. Clin Orthop Relat Res: 189-192.

16. Idler EL, Russell LB, Davis D (2000) Survival, functional limitations, and selfrated health in the NHANES I Epidemiologic Follow-up Study, 1992. First National Health and Nutrition Examination Survey. Am J Epidemiol 152: 874883.

17. Idler EL, KasI S (1991) Health perceptions and survival: do global evaluations of health status really predict mortality? J Gerontol 46: S55-65.

18. Burström B, Fredlund P (2001) Self rated health: Is it as good a predictor of subsequent mortality among adults in lower as well as in higher social classes? J Epidemiol Community Health 55: 836-840

19. Grof S (1980) LSD psychotherapy: Exploring the frontiers of the hidden mind Alameda, CA: Hunter House.

20. Ventegodt S, Andersen NJ, Kandel I (2009) Bio- and alternative medicine in conflict. Human rights protection of the alternative therapist. J Altern Med Res 1: 189-202.

21. Ornish D, Brown SE, Scherwitz LW, Billings JH, Armstrong WT, et al. (1990) Can lifestyle changes reverse coronary heart disease? The Lifestyle Heart Trial. Lancet 336: 129-133.

22. Ornish D, Scherwitz LW, Billings JH, Brown SE, Gould KL, et al. (1998) Intensive lifestyle changes for reversal of coronary heart disease. JAMA 280: 2001-2007. 